Chapter 8

\title{
Review of Iron Supplementation and Fortification
}

\author{
Lauren C. Ramsay and Christopher V. Charles \\ Additional information is available at the end of the chapter \\ http://dx.doi.org/10.5772/58987
}

\section{Introduction}

Iron deficiency anemia (IDA) is the most prevalent micronutrient condition globally, with nearly $50 \%$ of anemia cases being caused by iron deficiency according to the World Health Organization (WHO) [1]. While it is a condition that does not discriminate between the developed and developing world, the incidence is still higher in developing countries. In South-East Asia the WHO reported that $65.5 \%$ of preschool-age children suffer from anemia, and $48.2 \%$ and $45.7 \%$ of pregnant and non-pregnant women, respectively, also suffer from anemia, which represents the highest prevalence in the world [1].

As the most prevalent micronutrient condition in the world it is critical that there is a strong understanding of how to improve iron intake. In many cases this may involve taking iron supplement pills, however this is by no means the only approach that is currently being used. This chapter seeks to provide background information on iron deficiency and iron deficiency anemia (IDA), and review a number of current strategies currently being used to address these conditions around the world. This review is by no means exhaustive, but aims to cover a number of studies in each of the major iron deficiency intervention strategies.

\section{Iron deficiency and iron deficiency anemia}

The word anemia is derived from the Greek word òv $\alpha$ uí $\alpha$ anaimia, meaning "without blood," [2]. Anemia is a deficiency of red blood cells and/or hemoglobin resulting in a reduction of the oxygen-carrying capacity of blood [3]. An individual with a circulating hemoglobin concentration less than $120 \mathrm{~g} / \mathrm{L}$ is considered to be anemic, but this varies across age and sex based on iron requirement and hemoglobin thresholds, which can be seen in Figure 1 [1, 4]. 


\begin{tabular}{|l|l|}
\hline \multicolumn{2}{|l|}{ Hemoglobin thresholds used to define anemia } \\
\hline Age or Gender & Hemoglobin Threshold (g/L) \\
\hline Children (0.5-4.99 yrs) & 110 \\
\hline Children (5-11.99 yrs) & 115 \\
\hline Children (12-14.99 yrs) & 120 \\
\hline Von-pregnant Women ( $\geq 15.00$ yrs) & 120 \\
\hline Pregnanı Women ( $\geq 15.00$ yrs) & 110 \\
\hline Men $\geq 15.00$ yrs) & 130 \\
\hline
\end{tabular}

Figure 1. Hemoglobin concentration thresholds below which anemia is present

Anemia is caused by a long-term iron imbalance resulting in the depletion of bodily iron stores over time [2, 5]. Iron is a necessary component in the production of red blood cells, and so the absence of sufficient supplies results in decreased hemoglobin production and subsequently red blood cell production $[2,5,6]$. The focus of this chapter is on IDA, and this is typically a result of inadequate dietary intake, but could also be a result of excessive blood loss from trauma or post-partum hemorrhage, or other diseases such as parasitic infections, malaria, and inherited hemoglobin disorders [5, 6].

There are several risk factors of IDA, which have resulted in uneven distribution of prevalence around the world, with the highest concentration in developing countries in Africa and Asia [4]. The most commonly reported risk factors of IDA include: poverty [4,7]; local dietary staples such as rice which have low bio-availability of iron [8]; genetic hemoglobinopathies [9]; consumption of untreated water [10]; sex where typically females are more likely to experience IDA than males [11]; low parental educational attainment [10-12]; maternal anemia [13]; and food insecurity [13]. Based on the information presented above, it is clear that the determinants of IDA are complex and a number of social, ecological, biological and socioeconomic factors are at play. Across each study, however, poverty is the most salient predictor.

\subsection{Signs and symptoms of iron deficiency anemia}

The signs and symptoms vary among individuals but there are always adverse effects of IDA. Pregnant and postpartum women and young children are most susceptible to iron deficiency and IDA because of the high demands for iron that growth and pregnancy have [14]. These groups also experience some of the most severe symptoms [14].

Symptoms of IDA may include diminished work capacity, immune system dysfunction, neurocognitive impairment, dizziness, fatigue, and pallor $[2,6,7]$. Severe anemia can reduce significantly a woman's ability to survive giving birth due to bleeding during and after childbirth [14,15]. Additionally, pregnant women are at higher risk of preterm delivery when anemic [8]. For these reasons, anemia is considered to be a major contributor to maternal mortality in the developing world. The WHO reports that anemia is a factor in $20 \%$ of maternal deaths [16]. 
Children are also highly susceptible to adverse effects of IDA and experience additional signs and symptoms if left untreated. Anemic children may experience height and weight disturbances, slowing of learning and behavior development, and interruptions in physical or mental growth [12]. IDA can affect neurocognitive development, resulting in reduced psychomotor and cognitive abilities in children [2,17]. These are most often measured on standardized measures of mental development, cognitive function tests, psychomotor scales, and educational achievement tests [18]. The impaired cognitive and psychomotor development that children affected by iron deficiency or IDA experience is speculated to have a causal relationship to future earning potential, though study terms have not yet been long enough to quantify this [17]. This is thought to occur because of the direct relationship between iron and oxygen delivery to the brain and muscles [14].

\section{Iron in the body}

Iron is a critical component in many metabolic functions, particularly in delivering oxygen throughout the body as an essential component of red blood cells. The majority of human iron stores are found in hemoglobin [19]. Iron is a component of every human cell and plays a critical role in many biochemical reactions in the body. It is involved in oxygen transportation, energy production, cellular respiration, DNA synthesis and the production of dopamine and serotonin, which are essential to neurotransmission [7, 14, 20, 21]. The storage and transportation of iron are highly dependent on red blood cells morphology and the presence of sufficient amounts of hemoglobin. Iron is toxic when too much is stored in the body and may cause tissue damage when the iron capacity has been exceeded [5, 19]. This problem can be compounded by the very slow rate at which humans naturally lose iron [22].

\subsection{Dietary iron}

Dietary iron comes in two forms: heme and non-heme. Heme iron, which is more easily absorbed, comes from meat, poultry and fish. This source of iron is easily absorbed because it is delivered as the stable prophyrin complex and is unaffected by other food components [21]. Contrary to this, non-heme iron is more difficult to absorb and comes from cereals, legumes and some vegetables [21].

Non-heme iron from food comes in several different chemical forms and the elemental iron is dependent on this and the body's ability to recognize and absorb the iron. For example, the chemistry of ferric $\left(\mathrm{Fe}^{3+}\right)$ is much more dependent on $\mathrm{pH}$ levels in the stomach relative to ferrous $\left(\mathrm{Fe}^{2+}\right)$ iron; ferric iron requires a more acidic environment to be absorbed [21]. Thus, consuming vitamin $\mathrm{C}$ with dietary iron or iron supplementation can be a critical step to absorbing the maximum amount of elemental iron possible [5, 23]. Non-heme iron is further complicated in the presence of tannins (e.g. in tea) or phytate (e.g. in whole grains), as these are known to inhibit the absorption of non-heme iron [5, 21]. 


\section{Implications of parasitic infections and malaria}

\subsection{Helminths}

Infection with soil-transmitted intestinal helminths is a common problem among populations living primarily in rural areas of low-income countries. These parasites are a large, polyphyletic grouping of multicellular organisms that can generally be seen with the naked eye in their mature stages. Helminths typically include roundworm (Ascaris lumbricoides), whipworm (Trichuris trichiura) and the hookworms (Necator americanus and Ancylostoma duodenale) [24]. Some estimates suggest that more than 2 billion people on the planet are infected with one, or multiple helminths, with the highest prevalence occurring where sanitation is poor and water supplies are compromised [24].

Soil-transmitted helminths live in the intestine of an infected person, and are easily spread when a person comes into contact with the feces of an infected individual. This contact might result from the use of gardens, bushes or fields as an open latrine, or could result from the use of human feces as fertilizer that is intentionally sprayed onto crops and deposited into the soil. A new host is established when an uninfected person then unknowingly ingests the eggs of these parasites [25].

The association between parasite infection and anemia is well known and has been widely documented [26]. Primarily, the organisms cause gastrointestinal bleeding resulting in blood loss, lowered hemoglobin values, and resultant anemia. Further, some organisms disrupt nutrient absorption by damaging the mucosal surface of gut, leading to poor absorption of micronutrients. For example, the two significant hookworm species Ancylostoma duodenale and Necator americanus, produce 5000-10,000 and 10,000-25,000 eggs per day, resulting in $0.03 \mathrm{~mL}$ and $0.15-0.23 \mathrm{~mL}$ blood loss per day, respectively [27]. In addition, some hookworms release anti clotting factors that ensures continuous blood flow and thereby further leads to poor health outcomes [27].

\subsection{Malaria}

Malaria is a well-known cause of morbidity and mortality in the developing world, initiated by infection by parasites of the genus Plasmodium. Estimates of the burden of disease suggest that more than 515 million episodes occur annually, representing $18 \%$ of all childhood deaths in Sub-Saharan Africa [28, 29]. Anemia caused by malaria has a multi-factorial pathophysiology with unknown molecular mechanisms [30]. Research has shown that malaria is implicated in both the destruction of red blood cells through hemolysis of both infected and uninfected erythrocytes, but also through the decreased production of erythrocytes in the bone marrow [30]. Malarial anemia is therefore typically normocytic and normochromic with a distinct absence of reticulocytes.

Severe malarial anemia is of great public health concern because of the widespread prevalence of malaria in the developing world where access to appropriate healthcare is limited, and because children and pregnant women are the hardest hit by the condition [31]. Malarial anemia is most often observed in areas where high malarial transmission occurs [31]. Severe 
anemia caused by $P$ falciparum, one species of malarial infection, is responsible for approximately one-third deaths associated with the disease [30].

\section{Treating iron deficiency anemia}

Treating iron deficiency and iron deficiency anemia must continue to be a priority of governments, non-governmental organizations and international aid agencies alike. The ideal approach to addressing iron deficiency is a nutritious and well balanced diet that naturally provides adequate iron intake. However, this is not a reality in much of the developing world where subsistence comes from cereals with low iron bioavailability. This generates the need for a cost-effective, simple and easy to administer solution that may be found in supplementation and fortification. Food fortification is widely considered to be the most cost-effective approach to treating IDA, but this is not without its challenges [8]. While in the developed world fortified products are rampant, and often there are government regulations to ensure fortification of common food items (e.g. milk, breakfast cereals, and salt) this strategy can be less effective in the developing world. Even the smallest price increase in staple products in developing countries may be a deterrent to purchase and use them [8]. With escalating food prices, which peaked in the 2008 food crisis, households in developing countries were spending large shares of their incomes on food and commonly had to switch to cheaper but less nutritious foods to combat hunger [32]. In this case, the likelihood of households purchasing fortified foods may be a more difficult intervention to implement.

Currently several fortification approaches are being implemented; reference [33] describes three methods; 1) fortified products added during food processing (e.g. wheat flour); 2) fortification added at home during food preparation (e.g. multiple micronutrient powders); and 3) genetically engineered foods with enhanced nutrition (e.g. genetically engineered cereals). In general, iron fortification has been found to be very successful around the world; in a meta-analysis of randomized controlled trials for iron deficiency alleviation, 13 studies on iron fortification for women and 41 for children were assessed [34]. These studies included fortification via sodium iron ethylenediaminetetraacetic acid (NaFeEDTA), ferrous sulfate, fortified candies, fortified curry powder and ferrous pyrophosphate [34]. In these studies, efficaciousness of iron fortificants all showed significant results in improving hemoglobin concentration and reducing anemia in study populations [34]. A separate meta-analysis of 60 studies showed similar results: iron-fortified foods are efficacious in increasing hemoglobin concentrations and reducing IDA in study populations [35].

\section{Iron supplements}

The Lancet Series (2013) on maternal and child nutrition reported that during a trial of iron supplements in pregnant women they found a $67 \%$ reduction of iron deficiency anemia [36]. Additionally, in non-pregnant women a review of studies showed that intermittent iron 
supplementation was effective in reducing the risk of anemia by $27 \%$ [36]. This review also indicated that daily iron supplementation reduced the incidence of low birth weight by $19 \%$ [36]. Despite the high success rates of iron supplementation, distribution and cost become major concerns and make compliance in iron deficiency reduction strategies very difficult to navigate. Iron supplementation, often in the form of a pill or liquid, is an expensive option for treating iron deficiency and IDA, though the elemental iron present is much higher [8].

Apart from the difficulties of program implementation, a cost-effectiveness analysis was conducted in four subregions of the world (African subregion, South American subregion, European subregion and South-East Asian subregion) in order to compare the costeffectiveness (in \$USD) of iron supplementation versus fortification. This study showed that in the developed world supplementation was more cost-effective due to well-developed distribution chains already in place [18]. But despite the higher overall impact of iron supplementation on a population's health, fortification is more cost-effective in rural and developing communities [18].

\section{Case study: Iron fortified candies for children}

The use of micronutrient fortified candies and lozenges have been tested in some countries, including India and Indonesia. There are relatively few randomized controlled trials (RCTs) that assess the efficaciousness of this intervention compared to many of the other programs reviewed in this chapter.

Nutri-candy was developed as a strategy to alleviate iron deficiency and other micronutrient deficiencies in children aged 2-6 years, pregnant and lactating women and adolescent girls in the developing world [37].

\begin{tabular}{|ll|}
\hline Nutritional content of nutri-candy \\
\hline Nutrients & Levels per 3 gram lozenge \\
\hline Vitamin A & $500 \mathrm{IU}$ \\
Vitamin C & $10 \mathrm{mg}$ \\
Folic acid & $50 \mathrm{mcg}$ \\
Iron & $7 \mathrm{mg}$ \\
\hline
\end{tabular}

Figure 2. Nutri-candy nutritional content [37]

In India, where various manufacturers produce nutri-candy, more than five million people in four states take a fortified candy every day at a cost of US $\$ 1.33$ per person per year which includes the cost of transportation [38]. In West Bengal a study showed that while using nutricandy the prevalence of iron deficiency anemia reduced by $15 \%$. In Haryana another study 
took place that found the prevalence anemia changed from $50 \%$ at baseline to $9.6 \%$ in the group receiving a daily nutri-candy [39].

In Indonesia a similar study took place to test the impact of Vitella, a chewy fruit candy fortified with multiple micronutrients, on iron levels in children aged 4-6 years [40]. This study found that the hemoglobin concentration of children receiving the candies increased by $10.2 \mathrm{~g} / \mathrm{L}$, and anemia prevalence decreased by $42.1 \%$ after 12 weeks of intervention [40].

Based on these few studies in India and Indonesia the use of fortified candies should be further researched and incorporated into national strategies to alleviate iron deficiency. All studies reported high acceptability of the product both from caregivers and children [38-40]. If incorporated into school programs or other national strategies it may be very effective in reducing the burden of iron deficiency in low-income countries.

\section{Fortified staples}

Certain foods can be fortified after harvesting in order to deliver more iron during consumption and some can be genetically modified and bred to include more iron. The universal fortification of foods has been promoted as a strategy to address micronutrient deficiencies around the world. For example, in Canada and the United States it is a legal requirement to fortify milk during processing with Vitamins A, C and D [41, 42]. Universal food fortification is viewed to be an efficacious and cost-effective strategy to address IDA [43].

To use rice as an example, there are some strains of rice that have been genetically modified to have greater amounts of iron but the research in this area is still relatively new [44]. This can be achieved by introducing other genes to rice breeds that increase the storage of iron on polished white rice [45]. One way that this is done is by adding a gene from soybeans that adds the protein ferritin to rice, and studies have shown that this source of iron is bioavailable [45].

When rice is polished it loses much of its natural iron during this process and so a method of fortifying rice by applying an edible coating that improves the available iron in the rice [46]. A third way to fortify rice is by using a product called Ultra Rice which is a high-iron simulated rice grain that can be mixed in with regular rice and is highly accepted with no reports of bad texture or taste $[43,47]$.

During a randomized controlled trial in the Philippines iron fortified rice was proportionately mixed with regular rice to provide more available iron in a serving of rice. Hemoglobin concentrations of children in the study sites significantly increased from baseline to endline, and prevalence of anemia significantly decreased by $4.7 \%$ [48]. In Mexico when female factory workers were given fortified rice five days a week for six months iron status improved significantly, and the prevalence of anemia was reduced by $80 \%$ [43]. However, a study in Brazil found that the use of fortified rice only once weekly in child-care centres brought about similar results [47]. In addition to improved iron status, another study in Brazil found that study participants and their families exhibited a very high rate of acceptance of the fortified rice as part of their diet with no adverse effects or undesirable taste, colour or smell [49]. Iron 
fortified rice, with proven effectiveness in improving iron status as well as high acceptability of the product, may be an important part of national nutrition strategies.

Wheat flour and maize flour can also be fortified to be more iron rich, and may be a useful tool in addressing iron deficiency in communities where large amounts of wheat flour and its products are consumed [50]. The WHO supports the fortification of wheat and maize flour but suspects that it will be the most effective in reducing iron deficiency when it is mandated at the national level [51].

In a trial that assessed the efficacy of fortified wheat flour it was found that there was a lower prevalence of iron deficiency in women who consumed the fortified flour more regularly [50]. In a study conducted with Indian school children, iron fortified whole wheat flour, after seven months the prevalence of iron deficiency significantly declined from $62 \%$ to $21 \%$ [52].

Iron biofortified pearl millet has also been tested as an approach to address iron deficiency in communities of developing countries. A study in Benin found that consuming iron fortified pearl millet can double the absorption of iron in women and may be a highly effective approach to combatting iron deficiency in millet-eating communities [53].

Despite the improvement in hemoglobin concentration in trial communities, there were challenges and limitations to this approach for addressing iron deficiency and IDA. Primarily, the cost to households associated with switching to fortified products proved to be a challenge. For example, in the Philippines when the market was flooded with unfortified rice by the government, the population began purchasing the cheaper, unfortified variety rather than the iron-fortified rice that was slightly more expensive, despite the added benefit [48]. The other studies reviewed did not test the possibility of selling fortified products in markets so it is uncertain how this would work in different countries. It is likely that higher costs of fortified rice could be a barrier to the sale of the fortified rice, and this strategy may be difficult to sustain within a competitive market environment.

\section{Food fortification involving sodium ferritin}

It is possible to fortify condiments such as fish sauce and soy sauce, which are commonly consumed in Asian countries. A study conducted using iron fortified Thai fish sauce showed that iron absorption from ferric sulfate fortified fish sauce added to a meal of rice and vegetables showed positive results [54]. This suggests that fortified fish sauce may be an effective solution to combat iron deficiency in countries with high fish sauce use. A similar study conducted in Switzerland assessed NaFeEDTA fortified fish sauce and found that it is a potential fortification method to address iron deficiency and iron deficiency anemia [55]. In Cambodia fortified fish sauce and soy sauce are becoming more salient in the iron deficiency discussion and the government intends to legislate fortifying these condiments by 2015 [56]. In Vietnam, where fish sauce is consumed as part of the regular diet and produced locally, a study was conducted and found that women using iron fortified fish sauce for six months had an average higher hemoglobin concentrations by $8.7 \mathrm{~g} / \mathrm{L}$ than women who used regular fish 
sauce [57]. However, there are still challenges associated with fortifying condiments which include a changing of the colour of the sauce due to the addition of fortificants as well as political challenges to monitoring and rolling out this type of initiative [54,56].

While the cost-effectiveness ratio of this type of fortification has been positive, these analyses do not include the costs of potential health implications of high sodium diets [58]. Sodium is known to cause many adverse health problems including hypertension, increased risk of cardiovascular disease and increased risk of stroke [59]. It is possible that this type of intervention may promote excessive salt intake and the negative health impacts may outweigh the benefit of increased iron intake [60]. In fact, the WHO recommends that "the use of salt as the vehicle for new fortification initiatives other than iodine and fluoride should be discouraged," [60].

\section{Micronutrient Powders (MNPs)}

Micronutrient powders include any fortified powders that have at least two micronutrients in their composition. These powders are added to food being prepared in the home and then consumed, providing the benefits of the micronutrients they contain. This fortification method has received a great amount of attention in the nutrition world, as many micronutrient deficiencies are so prevalent around the world in both developed and developing countries and this strategy has the potential to address multiple deficiencies at once.

Sprinkles, a brand of MNP, were developed as a fortification method by creating a powder with iron and various micronutrients that can be 'sprinkled' on complementary foods before being fed to children [61, 62]. Various studies have shown that this is an effective method of increasing hemoglobin concentration and treating iron deficiency anemia in children [62-66]. In Cambodia two studies were conducted that demonstrated a significant decline in iron deficiency anemia among groups of children who were on a daily regiment of sprinkles versus a control group with no intervention [67, 68]. A study in Kenya assessed Sprinkles in a more real world setting by selling the product in local markets and found that in this situation they remained efficacious in reducing iron deficiency [69]. In India, where IDA is incredibly prevalent, the use of MNPs resulted in significantly reduced levels of IDA in children after 24 weeks of treatment [70]. In a meta-analysis conducted on 17 studies, micronutrient powders showed to significantantly reduce the prevalence of anemia by $34 \%$, iron deficiency anemia by $57 \%$, and improves hemoglobin concentration [71]. These results were from studies that occurred in various countries including Ghana, India, Bangladesh, Kenya, Pakistan and Haiti, which represents a number of regions in the world [71].

While the randomized clinical trials that have been conducted to test various MNPs have been successful, these are all in highly controlled situations. Studies have consistently showed success in improving biomarkers such as hemoglobin concentration and a reduction in anemia prevalence, however the adherence to such programs in a less-controlled environment may differ. Distribution, cultural cooking practices, and cultural perceptions of MNPs may impact the effectiveness of such programs, though in the case of MNPs there is potential for this 
intervention to remain efficacious. Micronutrient powders were accepted in many communities by caregivers around the world because they can be incorporated into the regular feeding practices [64,68]. In a study conducted in Bangladesh on sprinkle adherence [63] it showed that adherence was higher and hematological improvements were greater in groups who received more flexible instructions for use of 60 Sprinkles packets, rather than being told to use them daily. Further research into adherence and acceptability would be useful in order to develop a strong implementation strategy for different regions of the world.

\section{Taking advantage of adventitious sources of dietary iron}

\subsection{Cast iron pots}

Early studies demonstrated that cooking food in cast iron pots increases the iron content of certain foods and that this iron is bioavailable [72]. In the face of the global iron deficiency endemic, researchers believed that promoting the use of cast iron pots could be efficacious in reducing the incidence of iron deficiency and iron deficiency anemia. Studies have taken place that assess the effectiveness, cost effectiveness and acceptability of this approach.

A laboratory study was conducted in order to assess the impact on the iron contents of green leafy vegetables when cooked in different pots. This study demonstrated that the material of the pot plays a significant role in the bioavailable iron in green leafy vegetables, and those cooked in iron utensils had $9 \%$ more available iron than those cooked in non-iron pots [73]. There is still some debate whether or not the iron that leaches into the food is bioavailable, and the need for more extensive analysis into improving iron availability in more types of food such as maize and rice [74].

The main limitations of using cast iron pots to improve iron status are that there was low acceptability during randomized controlled trials [75-77]. Cast-iron pots were reported to be heavy, rust easily, and required more attention for cooking due being prone to higher cooking temperatures [75]. In one study it was found that participants were selling the cast iron pots in the market in order to supplement low family incomes [78]. On the other hand, cast iron pots required less wood for stoves since cooking times were faster, and the pots were considered to be very durable [75].

Despite increases in hemoglobin concentrations and a reduction in anemia in the trial communities, the use of cast iron pots is not an effective strategy for addressing iron deficiency and IDA in most cases. It is possible that in communities where the use of cast iron pots is already prevalent then promoting continued or increased use has potential to be a part of a larger strategy to eliminate iron deficiency and IDA because the communities already accept the use of these pots [79].

\subsection{The Lucky Iron Fish}

The Lucky Iron Fish, an intervention based on the same principles of cooking with a cast iron pot, has shown in a randomized controlled trial to be effective in increasing hemoglobin 
concentrations by $11.6 \mathrm{~g} / \mathrm{L}$, and reducing anemia by half in the study population, compared to the control group after 12 months [80]. This method involves boiling water or cooking soup with the Lucky Iron Fish (an iron ingot shaped like a common Cambodian fish) for 10 minutes and adding some form of ascorbic acid (citrus juice, most commonly) [80, 81].

While this has potential to be effective in addressing iron deficiency it has only been tested on women of reproductive age, and thus it is not certain that the Lucky Iron Fish will provide the right amount of iron for children. The clinical trial included only 6 pregnant women, and future research could seek out larger numbers of pregnant and lactating women to test the efficaciousness in these times of high iron demand. Furthermore, gaining a better understanding of the type of iron that leaches into water and foods would be beneficial, as would further testing of fortifiable foods. Additional challenges associated with this approach are predominantly surrounding acceptability and education, as this intervention requires significant behavior change in home practices. Research regarding the acceptability, adherence and cost-effectiveness of this strategy should take place in order to carefully compare it with alternate interventions to be included in a national nutrition strategy.

\section{Case study: Treating IDA in Cambodia in pregnant and post-partum women}

In Cambodia, it is reported that in 2006 63\% infants and young children suffer from anemia [67]. Current projects addressing iron deficiency in Cambodia include: the government supported supplementation for pregnant and post-partum women; Sprinkles; weekly iron folic acid supplements for women of reproductive age; helminth control; fortified foods such as rice and fish sauce; and the Lucky Iron Fish [82-84]. However, the official government stance, as advised by the World Health Organization (WHO) is for a supplementation program, and thus no official fortification program is currently in place or widely accepted by the numerous government and non-government groups working to address nutrition issues in Cambodia [84]. Recent research assessing the possibility of iron-fortified condiments has put fortification on the government's radar and is speculated to result in a change in government legislation [56]. Iron deficiency and its associated anemia remains a salient health issue in Cambodia and looking ahead a more multi-faceted approach may be necessary to successfully combat this challenge.

\subsection{Government supplementation program}

The following guidelines are followed by Health Centres in Cambodia: First contact during pregnancy: 60 iron/folic acid tablets provided; Second contact during pregnancy: 30 iron/folic acid tablets provided; Post-partum: 42 iron/folic acid tablets provided [84].

Iron supplementation is known to be incredibly effective due to the high bioavailability of iron [85-87]. This is especially important to ensure during pregnancy when iron demands of women are greater, and the risks can be more severe $[1,87]$. Daily iron supplementa- 
tion is the most effective strategy at protecting iron stores in women during pregnancy but large doses of iron are also associated with negative side effects [87]. The negative side effects may cause problems with compliance, thus damaging the effectiveness of these programs [86]. Currently an urgent need for evaluation on the government's supplementation program exists - as no studies have reported the effectiveness in at-need populations and monitoring the changes in iron deficiency and IDA.

In two focus groups held in February 2014 in the remote Preah Vihear province in northern Cambodia, women (approximately 30 in each village; Koh Ker and Ker) reported that less than $5 \%$ of participants visited a health centre during their pregnancy [88]. Collectively, the women reported that they were aware that at their community health centre they would have received free iron supplements for during pregnancy and after delivering their child. Despite this, women chose (by personal preference or circumstances dictated this) to deliver in their homes with a local midwife from their village. The health centres can be expensive to travel to and are far away from their villages, in the case of the two villages that were visited. The roads used to travel are barely passable, which only becomes more difficult during the rainy season (June - November) [88]. This suggests that in some parts of Cambodia the government initiatives may not be reaching marginalized populations, the population that demonstrates the greatest need.

\section{Discussion}

There is a significant difference between fortification and supplementation with regards to economic feasibility, government involvement and effectiveness in improving health. Fortification has an opportunity to be a more cost-effective and efficacious treatment for iron deficiency and iron-deficiency anemia than supplementation in many developing countries. While iron supplements should continue to be a critical component of a national strategy to alleviate iron deficiency and its associated anemia, particularly in times of high iron demands such as pregnancy, a multifaceted approach should be developed to more effectively combat this micronutrient deficiency.

Each of the fortification strategies reviewed in this chapter were efficacious in improving iron status in a controlled environment. However in many cases this does not provide assurance that adopting these strategies will be effective in every community. Adherence and acceptability are critical to the success of these interventions, but most RCTs do not assess these conditions, as it can be difficult with the need for controlled settings to conduct trials. As with many other development strategies, the approach will vary across, and even within countries, which makes developing guidelines for the treatment of ID and IDA difficult. What works in one country will likely not work in the exact same way in a neighbouring country, and the same can be said from one village to the next. However, some of the interventions that were reviewed in this chapter demonstrated greater success in different regions of the world than others. The use of cast-iron pots did not prove to be an acceptable strategy in most countries due to the preference for lighter, easier to clean aluminum pots. 
Multi-micronutrient powders have proven to be consistently effective in RCTs in alleviating iron deficiency in children. Both government distribution channels and selling sachets of MNPs in a market setting have been successful. A limitation of this approach is that few studies have tested the efficaciousness of MNPs in treating ID and IDA in groups other than children. The few studies conducted testing the effectiveness of MMPs in pregnant women the results are modest, and has been suggested that alone they are not adequate to address maternal iron deficiency [89]. There are still challenges being addressed with this approach but it has the potential to be efficacious as part of a national strategy. Since women of reproductive age are in great need of iron fortification programs multi-micronutrient powders should not be the sole component of a national approach, but could be included as part of a strategy to improve children's iron status.

Similarly, biofortified staples such as rice and wheat flour were highly acceptable and effective in decreasing ID and IDA. Future research could focus on cereals beyond rice and wheat flour and the possibility of enriching them with iron either during the breeding and growing of a crop, or during processing. Further research surrounding genetically modifying rice to contain more iron is required, otherwise the iron must always be added during processing and risks being rinsed off when the rice is washed. Biofortified staples can be very sensitive to market prices, which could be a serious limitation in competitive market settings. This approach would work if governments are able to pass legislation that mandates all of the main staple product in a region be fortified with iron. The challenges associated with this are difficult, but the positive health outcomes have the potential to be vast.

Ultimately, for any of these fortification strategies to be successfully implemented extensive education and health behavior campaigns must take place. Properly planned education materials and outreach can promote adherence and acceptability at a community level. Iron deficiency can sometimes not be felt immediately by an individual, especially when compared to hunger, which is why it is often called "hidden hunger," along with other micronutrient deficiencies. This is relevant to education and behavior change because certain behaviours that aren't routine (such as washing your hands, or taking an iron supplement) may not seem credible or urgent because there are no immediately visible health concerns [90]. This may pose a challenge to communicate the future implications and the less tangible impacts of these things on their health in order to promote healthier behaviours.

One of the largest and most difficult questions is then: who is responsible? At this point in the battle to alleviate iron deficiency and IDA the most dangerous thing that can be done is nothing. Inaction in the face of this epidemic will benefit no one, and the negative health consequences of iron deficiency will persist. The cognitive and physical development consequences and threat to maternal health that iron deficiency poses are severe and will only continue to be the most prevalent nutrition issue in the world without the combined support of governments, aid agencies and non-government agencies alike. 


\section{Author details}

Lauren C. Ramsay ${ }^{1 *}$ and Christopher V. Charles ${ }^{2}$

*Address all correspondence to: lauren@lauren-ramsay.com

1 Department of Biomedical Sciences, University of Guelph, Guelph, Canada

2 Michael G. DeGroote School of Medicine, McMaster University, Hamilton, Canada

\section{References}

[1] de Benoist, B., McLean, E., Egli, I., Cogswell, M. Worldwide prevalence of anaemia 1993-2005. WHO Global Database on Anaemia 2008

[2] Clark, S. F. Iron deficiency anemia. Nutrition in Clinical Practice 2008; 23(2) 128-41. doi:10.1177/0884533608314536

[3] Loney, M., Chernecky, C. Anemia. Continuing Education 2000; 27(6) 951-962.

[4] Balarajan, Y., Ramakrishnan, U., Ozaltin, E., Shankar, A. H., Subramanian, S. V. Anemia in low-income and middle-income countries. The Lancet 2011; 378 2123-35. doi: 10.1016/S0140-6736(10)62304-5

[5] the 21st century. Therapeutic Advances in Gastroenterology 2011; 4(3) 177-84. doi: $10.1177 / 1756283 \times 11398736$

[6] Means, R. T. Iron deficiency anemia. Hematology 2013 18(5), 305-6. doi: 10.1179/1024533213Z.000000000197

[7] Charles, C. V. Iron Deficiency Anemia: A Public Health Problem of Global Proportions, Public Health-Methodology, Environmental and Systems Issues, Prof. Jay Maddock (Ed.), ISBN: 978-953-51-0641-8, InTech; 2012 p109-130. Available from: http://www.intechopen.com/books/public-health-methodology-environmental-andsystems-issues/iron-deficiency-anemia-a-public-health-problem-of-global-proportions (Accessed 20 July, 2013)

[8] Lynch, S. R. Why nutritional iron deficiency persists as a worldwide problem. The Journal of Nutrition 2011; 141(4) 763S-768S. doi:10.3945/jn.110.130609

[9] George, J., Yiannakis, M., Main, B., Devenish, R., Anderson, C., An, U. S., Williams, S. M., Gibson, R. S. Genetic hemoglobin disorders, infection, and deficiencies of iron and vitamin A determine anemia in young Cambodian children. The Journal of Nutrition 2012; 142(4) 781-7. doi:10.3945/jn.111.148189 
[10] Cotta, R. M., Oliveira, F. C., Magalhães, K. A., Ribeiro, A. Q., Sant'Ana, L. F., Priore, S. E., Franceschini, S. C. Social and biological determinants of iron deficiency anemia. Cadernos De Saúde Pública 2011; 27(2) S309-20.

[11] Tengco, L. W., Rayco-Solon, P., Solon, J. A., Sarol, J. N., Solon, F. S. Determinants of anemia among preschool children in the Philippines. Journal of the American College of Nutrition 2008; 27(2) 229-43.

[12] Choi, H. J., Lee, H. J., Jang, H. B., Park, J. Y., Kang, J. H., Park, K. H., Song, J. Effects of maternal education on diet, anemia, and iron deficiency in Korean school-aged children. BMC Public Health 2011; 11 870-878. doi:10.1186/1471-2458-11-870

[13] Pasricha, S. R., Black, J., Muthayya, S., Shet, A., Bhat, V., Nagaraj, S., Prashanth, N. S., Sudarshan, H., Biggs, B., \& Shet, A. S. Determinants of anemia among young children in rural India. Pediatrics 2010; 126(1) e140-9. doi:10.1542/peds.2009-3108

[14] Stoltzfus, R. J., Mullany, L., Black, R. E. Iron deficiency anemia. Comparative quantification of health risks 2004; 1 164-209.

[15] Brabin, B., Hakimi, M., Pelletier, D. An analysis of anemia and pregnancy-related maternal mortality. The Journal of Nutrition 2001; 131(2) 604S-615S.

[16] World Health Organization. Micronutrient Deficiencies: Iron Deficiency Anemia. Available from http://www.who.int/nutrition/topics/ida/en/ (Accessed 5 July 2014).

[17] Horton, S., Ross, J. The economics of iron deficiency. Food Policy 2003; 28 51-75.

[18] Baltussen, R., Knai, C., Sharan, M. Iron fortification and iron supplementation are cost-effective interventions to reduce iron deficiency in four subregions of the world. The Journal of Nutrition 2004; 134(10) 2678-2684

[19] McLaren, G. D., Muir, W. A., Kellermeyer, R. W. Iron overload disorders: Natural history, pathogenesis, diagnosis, and therapy. Critical Reviews in Clinical Laboratory Sciences 1983; 19(3) 205-266.

[20] Singh, M. Role of micronutrients for physical growth and mental development. Indian Journal of Pediatrics 2004; 71(1) 59-62.

[21] Theil, E. C. Iron, ferritin, and nutrition. Annual Review of Nutrition 2004; 24 327-43. doi:10.1146/annurev.nutr.24.012003.132212

[22] Conrad, M. E., Umbreit, J. N. Iron absorption and transport-an update. American Journal of Hematology 2000; 64(4) 287-98.

[23] Sobieraj, D. Heme or non-heme? An overview of iron supplements. Available from https://www.cedrugstorenews.com/userapp/lessons/page_view_ui.cfm?lessonuid=\&pageid=86975F921481E289FB3858040268C2A0 (Accessed 3 July 2014) 
[24] World Health Organization. Soil transmitted helminthiases. World Health Organization, Geneva, Switzerland 2012. Available from http://whqlibdoc.who.int/publications/2012/9789241503129_eng.pdf?ua=1 (Accessed 15 July 2014).

[25] Centres for Disease Control and Prevention. Parasites: Soil transmitted helminthes. http://www.cdc.gov/parasites/sth/ (Accessed 15 July 2014).

[26] World Health Organization. Working to overcome the global impact of neglected tropical diseases. World Health Organization 2010, Geneva, Switzerland. Available from http://whqlibdoc.who.int/publications/2010/9789241564090_eng.pdf (Accessed 15 July 2014).

[27] Shetty, P. S. Nutrition, Immunity and Infection. Cambridge: Cambridge University Press; 2010

[28] Rowe A. K., Rowe S. Y., Snow R. W. The burden of malaria mortality among African children in the year 2000. Int J Epidemiol 2006; 35 691-704.

[29] Snow R. W., Guerra C. A., Noor A. M., Myint H. Y., Hay S. I. The global distribution of clinical episodes of Plasmodium falciparum malaria. Nature 2005; 434 214-217.

[30] Haldar K., Mohandas, N. Malaria, erythrocytic infection, and anemia. Hematology 2009; 1 87-93.

[31] Lamikanra, A. A., Brown, D., Potocnik, A., Casals-Pascual, C., Langhorne, J., Roberts, D. Malarial anemia: of mice and men. Blood 2007. DOI 10.1182/blood-2006-09-018069.

[32] Brinkman, H., de Pee, S., Sanogo, I., Subran, L., Bloem, M. W. High food prices and the global financial crisis have reduced access to nutritious food and worsened nutritional status and health. The Journal of Nutrition 2009; 140(1) 153S-161S.

[33] Berry, J., Mukherjee, P., Shastry, G. Taken with a grain of salt? Micronutrient fortification in South Asia. Economic Studies 2012; 58(2) 422-449.

[34] Das, J., Salam, R., Kumar, R., Bhutta, Z. Micronutrient fortification of food and its impact on woman and child health: a systematic review. Systematic Reviews 2013; 2(67)

[35] Gera, T., Sachdev, H., Boy, E. Effect of iron-fortified foods on hematologic and biological outcomes: systematic review of randomized controlled trials. The American Journal of Clinical Nutrition 2012; 96 309-24.

[36] Bhutta, Z., Das, J. K., Rizvi, A., Gaffey, M. F., Walker, N., Horton, S., Webb, P., Lartey, A., Black, R. E. Evidence-based interventions for improvement of maternal and child nutrition: what can be done and at what cost? The Lancet 2013; 382(9890) 452-477.

[37] The Micronutrient Initiative. Fortified Candies/Lozenges. The Micronutrient Initiative, Ottawa, Canada. Available from http://www.micronutrient.org/CMFiles/What \%20we\%20do/New\%20Solutions\%20-\%20Emergencies/Lozenges.pdf (Accessed 22 July 2014). 
[38] Bulusu, S., Joshi, T. P. Suck it and see: Fortified lozenges delivering multiple micronutrients to the community in India. Nutrition 2006; 3 16-17.

[39] Anand, K., Lakshmy, R., Janakarajan, V. N., Ritvik, A., Misra, P. Effect of consumption of micronutrient fortified candies on the iron and vitamin A status of children aged 3-6 years in rural Haryana. Indian Pediatrics 2007; 44 823-829.

[40] Sari, M., Bloem, M. W., de Pee, S., Schultink, W. J., Sastroamidjojo, S. Effect of ironfortified candies on the iron status of children aged 4-6 y in East Jakarta, Indonesia. The American Journal of Clinical Nutrition 2001; 73 1034-1039.

[41] Canadian Food Inspection Agency. Dairy Vitamin Addition. http://www.inspection.gc.ca/food/dairy-products/manuals-inspection-procedures/dairy-vitamin-addition/eng/1378179097522/1378180040706 (accessed 15 July 2014).

[42] Institute of Medicine of the National Academies. Dietary reference intakes guiding principles for nutrition labeling and fortification. Washington, D.C.: National Academies Press; 2003.

[43] Hotz, C., Porcayo, M., Onofre, G., García-Guerra, A., Elliott, T., Jankowski, S., Greiner, T. Efficacy of iron-fortified ultra rice in improving the iron status of women in Mexico. Food \& Nutrition Bulletin 2008; 29(2) 140-149.

[44] Stein, A. J., Meenakshi, J. V., Qaim, M., Nestel, P., Sachdev, H. P., Bhutta, Z. A. Potential impacts of iron biofortification in India. Social Science \& Medicine 2008; 66(8) 1797-808. doi:10.1016/j.socscimed.2008.01.006

[45] Slamet-loedin, I. H. "Iron-clad" rice. Rice Today 2011; 10(3) 46.

[46] Mridula, D., Pooja, J. (2014). Preparation of iron-fortified rice using edible coating materials. International Journal of Food Science \& Technology 2014; 49(1) 246-252. doi:10.1111/ijfs.12305

[47] Arcanjo, F. P., Santos, P. R., Arcanjo, C. P., Amancio, O. M., Braga, J. A. Use of ironfortified rice reduces anemia in infants. Journal of Tropical Pediatrics 2012; 58(6) 475-80. doi:10.1093/tropej/fms021

[48] Angeles-Agdeppa, I., Saises, M., Capanzana, M., Juneja, L. R., Sakaguchi, N. Pilotscale commercialization of iron-fortified rice: Effects on anemia status. Food \& Nutrition Bulletin 2011; 32(1) 3-12.

[49] Beinner, M. A., Velasquez-Meléndez, G., Pessoa, M. C., Greiner, T. Iron-fortified rice is as efficacious as supplemental iron drops in infants and young children. The Journal of Nutrition 2009; 140(1) 49-53. doi:10.3945/jn.109.112623

[50] Grimm, K. A., Sullivan, K. M., Alasfoor, D., Parvanta, I., Suleiman, A. J. M., Kaur, M., Al-Hatima, F. O., Ruth, L. J. Iron-fortified wheat flour and iron deficiency among women. Food \& Nutrition Bulletin 2012; 33(3) 180-186.

[51] World Health Organization. Recommendations on Wheat and Maize Flour Fortification. World Health Organization, Geneva, Switzerland 2009. Available from http:// 
www.who.int/nutrition/publications/micronutrients/wheat_maize_fort.pdf cessed 21 July 2014).

[52] Muthayya, S., Thankachan P., Hirve S., Amalrajan V., Thomas T., Lubree H., Agarwal D., Srinivasan K., Hurrell R. F., Yajnik C. S., Kurpad A. V. Iron fortification of whole wheat flour reduces iron deficiency and iron deficiency anemia and increases body iron stores in Indian school-aged children. Journal of Nutrition 2012; 142(11) 1997-2003.

[53] Cercamondi, C. I., Egli, I. M., Mitchikpe, E., Tossou, F., Zeder, C., Hounhouigan, J. D., Hurrell, R. F. Total iron absorption by young women from iron-biofortified pearl millet composite meals is double that from regular millet meals but with less than that from post-harvest iron-fortified millet meals. Journal of Nutrition 2013; 143(9) 1376-1382.

[54] Walczyk, T., Tuntipopipat, S., Zeder, C., Sirichakwal, P., Wasantwisut, E., Hurrell, R. Iron absorption by human subjects from different fortification compounds added to Thai fish sauce. European Journal of Clinical Nutrition 2005; 59 668-674.

[55] Fidler, M., Davidson, L, Walczyk, T., Hurrell, R. Iron absorption from fish sauce and soy sauce fortified with sodium iron EDTA. The American Journal of Clinical Nutrition 2003; 78 274-278.

[56] Theary, C., Panagides, D., Laillou, A., Vonthanak, S., Kanarath, C., Chhorvann, C., Sambath, P., Sowath, S., Moench-Pfanner, R. Fish sauce, soy sauce, and vegetable oil fortification in Cambodia: Where do we stand to date?. Food and Nutrition Bulletin 2013; 34(2) S62-72.

[57] Thuy, P.V., Berger, J., Davidsson, L., Khan, N. C., Lam, N. T., Cook, J. D., Hurrell, R. F., Khoi, H. H. Regular consumption of NaFeEDTA-fortified fish sauce improves iron status and reduces the prevalence of anemia in anemic Vietnamese women. American Journal of Clinical Nutrition 2003; 78(2) 284-290.

[58] Longfils, P., Monchy, D., Weinheimer, H., Chavasit, V., Nakanishi, Y., Schumann, K. A comparative intervention trial on fish sauce fortified with NaFe-EDTA and FeSO4+citrate in iron deficiency anemic school children in Kampot, Cambodia. Asia Pac J Clin Nutr 2008; 17(2) 250-257.

[59] World Health Organization. Guideline: Sodium intake for adults and children. World Health Organization, Geneva, Switzerland 2012. Available from http:// www.who.int/nutrition/publications/guidelines/sodium_intake_printversion.pdf (Accessed 10 July 2014).

[60] World Health Organization. Salt reduction and iodine fortification strategies in public health. World Health Organization, Geneva, Switzerland 2013. Available from: http://www.who.int/nutrition/publications/publichealth_saltreduc_iodine_fortification/en/ (Accessed 10 July 2014). 
[61] Zlotkin, S., Arthur, P., Antwi, K. Y., Yeung, G. Treatment of anemia with microencapsulated ferrous fumarate plus ascorbic acid supplied as sprinkles to complementary (weaning) foods. The American Journal of Clinical Nutrition 2001; 74(6) 791-795.

[62] Zlotkin, A., Shauer, C., Christofides, A., Sharieff, W., Tonderu, M. C., Zlauddin Hyder, S. M. Micronutrient Sprinkles to control childhood anaemia. Health in Action 2005; 2(1) 24-28

[63] Ip, H., Hyder, S., Haseen, F., Rahman, M., Zlotkin, S. Improved adherence and anemia cure rates with flexible administration of micronutrient Sprinkles: a new public health approach to anemia control. European Journal of Clinical Nutrition 2009; 63 165-172.

[64] Macharia-Mutie, C. W., Moretti, D., Van den Briel, N., Omusundi, A. M., Mwangi, A. M., Kok F. J., Zimmerman, M. B., Brouwer, I. D. Maize porridge enriched with a micronutrient powder containing low-dose iron as NaFeEDTA but not amaranth grain flour reduces anemia and iron deficiency in Kenyan preschool children. The Journal of Nutrition 2012; 142(9) 1756-63. doi:10.3945/jn.112.157578

[65] Troesch, B., van Stuijvenberg, M. E., van Stujivenberg, M. E., Smuts, C. M., Kruger, H. S., Biebinger, R., Hurrell, R. F., Baumgartner, J., Zimmermann, M. B. A micronutrient powder with low doses of highly absorbable iron and zinc reduces iron and zinc deficiency and improves weight-for-age z-scores in South African children. The Journal of Nutrition 2011; 141(2) 237-42. doi:10.3945/jn.110.129247

[66] Serdula, M. K., Lundeen, E., Nichols, E. K., Imanalieva, C., Minbaev, M., Mamyrbaeva, T., Timmer, A., Aburto, N. J. Effects of a large-scale micronutrient powder and young child feeding education program on the micronutrient status of children 6-24 months of age in the Kyrgyz Republic. European Journal of Clinical Nutrition 2013; 67(7) 703-7. doi:10.1038/ejcn.2013.67

[67] Giovannanini, M., Sala, D., Usuelli, M., Livio, L., Francescato, G., Braga, M., Radaelli, G., Riva, E. Double blind, placebo-controlled trial comparing effects of supplementation with two different combinations of micronutrients delivered as sprinkles on growth, anemia, and iron deficiency in Cambodian infants. Journal of Pediatric Gastroenterology and Nutrition 2006; 42 306-312.

[68] Jack, S., Ou, K., Chea, M., Chhin, L., Devenish, R., Dunbar, M., Eang, C., Hou, K., Ly, S., Khin, M., Prak, S., Reach, R., Talukder, A., Tokmoh, L., Leon de la Barra, S., Hill, P., Herbison, P., Gibson, R. Effect of micronutrient Sprinkles on reducing anemia. Arch Pediatri Adolesc Med 2012; 166(9) 842-850.

[69] Suchdev, P. S., Ruth, L. J., Woodruff, B. A., Mbakaya, C., Mandava, U., Flores-Ayala, R., Jefferds, M. E., Quick, R. Selling sprinkles micronutrient powder reduces anemia, iron deficiency, and vitamin A deficiency in young children in western kenya: A cluster-randomized controlled trial. The American Journal of Clinical Nutrition 2012; 95(5) 1223-30. doi:10.3945/ajcn.111.030072 
[70] Varma J. L., Das S., Sankar R., Mannar M. G., Levinson FJ, Hamer D. H. Communitylevel micronutrient fortification of a food supplement in India: a controlled trial in preschool children aged 36-66 mo. American Journal of Clinical Nutrition 2007; 85(4) 1127-1133.

[71] Salam, R., MacPhail, C., Das, J., Bhutta, Z. Effectiveness of micronutrient powders (MNP) in women and children. BMC Public Health 2013; 13(3) S22-S32.

[72] Drover, D.P., Maddocks, I. Iron content of native foods. Papua New Guinea Med. J. $1975 ; 18$ 15-17.

[73] Kumari, M., Gupta, S., Lakshmi, A., Prakash, J. Iron bioavailability in green leafy vegetables cooked in different utensils. Food Chemistry 2004; 86(2) 217-222. doi: 10.1016/j.foodchem.2003.08.017

[74] Sharieff, W., Dofonsou, J., Zlotkin, S. Is cooking food in iron pots an appropriate solution for the control of anaemia in developing countries? A randomised clinical trial in Benin. Public Health Nutrition 2008; 11(9) 971-7. doi:10.1017/S1368980007001139

[75] Geerligs, P., Brabin, B., Mkumbwa, A., Broadhead, R., Cuevas, L. E. Acceptability of the use of iron cooking pots to reduce anaemia in developing countries. Public Health Nutrition 2002; 5(5) 619-24. doi:10.1079/PHN2002341

[76] Geerligs, P. P., Brabin, B., Mkumbwa, A., Broadhead, R., Cuevas, L. E. The effect on haemoglobin of the use of iron cooking pots in rural Malawian households in an area with high malaria prevalence: A randomized trial. Tropical Medicine \& International Health 2003; 8(4) 310-315.

[77] Geerligs, P. D., Brabin, B. J., Omari, A. Food prepared in iron cooking pots as an intervention for reducing iron deficiency anaemia in developing countries: A systematic review. Journal of Human Nutrition and Dietetics 2003; 16(4) 275-281.

[78] Tripp, K., Mackeith, N., Woodruff, B. A., Talley, L., Mselle, L., Mirghani, Z., Abdalla, F., Bhatia, R., Seal, A. J. Acceptability and use of iron and iron-alloy cooking pots: Implications for anaemia control programmes. Public Health Nutrition 2010; 13(1) 123-30. doi:10.1017/S1368980009005928

[79] Kapur, D., Agarwal, K. N., Agarwal, D. K. Nutritional anemia and its control. The Indian Journal of Pediatrics 2002; 69(7) 607-616.

[80] Charles, C. V. Happy Fish: a novel supplementation technique to prevent iron deficiency anemia in women in rural Cambodia. PhD Thesis. University of Guelph; 2012

[81] Charles, C. V., Dewey, C. E., Daniell, W. E., Summerlee, A. J. Iron-deficiency anaemia in rural Cambodia: Community trial of a novel iron supplementation technique. European Journal of Public Health 2011; 21(1) 43-8. doi:10.1093/eurpub/ckp237

[82] Helen Keller International. Iron Deficiency in Cambodia: The Need for Iron Supplementation Among Preschool-aged Children. Phnom Penh, Cambodia 2001. Available 
from http://www.hki.org/research/CmbNutrBul_vol2_iss6.pdf (Accessed 3 July 2014).

[83] Charles, C. V., Summerlee, A. J., Dewey, C. E. Anemia in Cambodia: Prevalence, etiology and research needs. Asia Pac J Clin Nutr 2012; 21(2) 171-181.

[84] Cambodia Ministry of Health. National guidelines for the use of iron folate supplementation to prevent and treat anemia in pregnant and post-partum women. Phnom Penh, Cambodia 2007. Available from http://www.a2zproject.org/pdf/National \%20Guidelines\%20for\%20the\%20Use\%20of\%20Iron\%20Folate\%20Supplementation $\% 20$ to\%20Prevent $\% 20$ and $\% 20$ Treat $\% 20$ Anemia $\% 20$ in\%20Pregnant $\% 20$ and $\% 20$ PostPartum\%20Women.pdf (Accessed 3 July 2014).

[85] Kanal, K., Busch-Hallen, J., Cavalli-Sforza, T., Crape, B., Smitasiri, S. Weekly iron-folix acid supplements to prevent anemia among Cambodian women in three settings: process and outcomes of social marketing and community mobilization. Nutrition Reviews 2005; 63(12) 126-133.

[86] Allen, L.H. Iron supplements: scientific issues concerning efficacy and implications for research and programs. Journal of Nutrition 2002; 132(4) 4813S-4819S.

[87] Beard, J.L. Effectiveness and strategies of iron supplementation during pregnancy. American Journal of Clinical Nutrition 2000; 71(5) 288s-1294s.

[88] Ramsay, L. Use of health centres in rural Preah Vihear province, Cambodia. Unpublished manuscript 2014.

[89] Allen, L.H., Peerson, J.M., Olney, D.K. Provision of multiple rather than two or fewer micronutrients more effectively improves growth and other outcomes in micronutrient-deficient children and adults. Journal of Nutrition 2007; 139(5) 1022-1030.

[90] Aboud, F., Singla, D. Challenges to changing health behaviours in developing countries: a critical overview. Social Science \& Medicine 2012; 75 589-594. 
